\title{
Does the wind stress always damp an oceanic eddy?
}

\author{
Fangyuan Teng ${ }^{1,2,3}$, Changming Dong ${ }^{1,2,4^{*}}$, Jinlin $\mathrm{Ji}^{1}$, Brandon J. Bethel ${ }^{1}$, Aijun Pan ${ }^{3}$ and Chi X ${ }^{5}$
}

\begin{abstract}
Up to now, the literature has shown that the relative wind stress does negative work on ocean mesoscale eddies. In other words, the relative wind stress inhibits the development of the eddies. However, based on a newly derived simplified theoretical model, the present study finds that under the action of a steady and uniform wind field, eddies can rapidly obtain kinetic energy from the wind field following several hours of adaption and adjustment, in which the wind stress transitions from doing negative to positive work. The finding is supported by the fact that the relative wind stress work on oceanic eddies over the northeastern tropical Pacific ocean is positive with the nearly constant gap wind. This implies that energy input from the wind is sensitive to eddy velocity structure, and hence, wind stress is not always a killer of eddies.
\end{abstract}

Keywords: Ocean mesoscale eddy, Wind work, Eddy killer, Wind stress, Work done by stress

\section{Introduction}

Sea surface winds are a major energy source for the oceanic motions. How the wind energy is transferred into the ocean is an important topic in the climatic studies. Since mesoscale oceanic eddies are ubiquitous phenomena in world oceans (Dong et al. 2014), understanding how oceanic eddies affects the wind energy input into the ocean has received significant attentions in oceanographic community, e.g. Zhai et al (2012), Xu et al (2016), Renault et al. $(2016,2018)$. The power that wind energy inputs into the ocean is estimated by the product of the wind stress and the sea surface velocity (Faller 1968; Oort et al. 1994; Wunsch 1998) and is as follows:

$$
P=\vec{\tau} \cdot \vec{U}
$$

where $P$ is the power per unit area of work done on the ocean by the wind, $\vec{\tau}$ is the sea surface wind stress, $\vec{U}$ is the sea surface velocity. The sea surface wind stress is

*Correspondence: cmdong@nuist.edu.cn

${ }^{1}$ Oceanic Modeling and Observation Laboratory, School of Marine Sciences, Nanjing University of Information Science and Technology, Nanjing, China

Full list of author information is available at the end of the article usually calculated in the form of the second power of relative wind speed (Qin 1980; Dewar and Flierl 1987; Pacanowski 1987; Scott and Xu 2009):

$$
\overrightarrow{\tau_{\text {rel }}}=\rho_{a} C_{D}\left(\overrightarrow{U_{a}}-\vec{U}\right)\left|\overrightarrow{U_{a}}-\vec{U}\right|
$$

where $\rho_{a}$ is the air density above the sea surface $\left(1.25 \mathrm{~kg} \cdot \mathrm{m}^{-3}\right), \vec{U}_{a}$ indicates the atmospheric wind speed at a height of $10 \mathrm{~m}$ above the sea surface, $C_{d}$ represents the drag coefficient of sea surface, which performs the momentum transfer efficiency between atmosphere and ocean, and is dependent on wind speed, currents, waves, sea surface roughness, and stability amongst other factors (Charnock 1955; Garratt 1977; Wu 1980; Powell et al. 2003; Donelan et al. 2004; Makin 2005; Kara et al. 2007; Zhao et al. 2015). As ocean current velocities are usually less than $1 m \cdot s^{-1}$, which is much smaller than the sea surface wind speed, the surface wind stress exerted by the atmosphere on the ocean can be approximately expressed as a function of the atmospheric wind (Bunker 1976; Bye 1985):

$$
\overrightarrow{\tau_{a b s}}=\rho_{a} C_{D} \overrightarrow{U_{a}}\left|\overrightarrow{U_{a}}\right|
$$

\section{Springer Open}

(c) The Author(s) 2021. Open Access This article is licensed under a Creative Commons Attribution 4.0 International License, which permits use, sharing, adaptation, distribution and reproduction in any medium or format, as long as you give appropriate credit to the original author(s) and the source, provide a link to the Creative Commons licence, and indicate if changes were made. The images or other third party material in this article are included in the article's Creative Commons licence, unless indicated otherwise in a credit line to the material. If material is not included in the article's Creative Commons licence and your intended use is not permitted by statutory regulation or exceeds the permitted use, you will need to obtain permission directly from the copyright holder. To view a copy of this licence, visit http://creativecommons.org/licenses/by/4.0/. 
The primary difference between Eqs. (3) and (2) is that Eq. (3) ignores the contribution of sea surface velocity and only considers the wind speed. In this study, Eq. (3) is termed the absolute wind stress, while Eq. (2) considering the sea surface current is termed the relative wind stress.

It has been suggested by the literature that the work of the relative wind stress on the ocean could be decreased significantly when oceanic mesoscale eddies are presented in oceanic models with the relative wind stress used as suggested by Duhaut and Straub (2006), Dawe and Thompson (2006), Zhai and Greatbatch (2007), Scott and Xu (2009), Zhai et al (2012), Xu et al (2016), Renault et al. (2016, 2018), Yu et al (2018). These studies identify that if the relative wind stress is used rather than the absolute wind stress, a decrease of $17-35 \%$ in the input of the energy to the ocean could be observed and this is linked to the influence of the ubiquitous mesoscale ocean eddies. Particularly, Hughes and Wilson (2008), Zhai et al. (2012), Xu et al (2016), and Renault et al (2018) find that relative wind stress can damp the development of ocean mesoscale eddies. Xu et al. (2016) used satellite observational data to quantify the work of the global wind stress on mesoscale eddies, and their study shows that the work of relative wind stress on mesoscale eddies is negative in most oceanic regions. Considering the role of wind stress in damping the eddy intensity and activity, Renault et al. (2018) term the wind stress to be an 'eddy killer'

However, so far, these studies have only considered the transient response of the eddies to the relative wind stress and ignored the dynamic response of ocean mesoscale eddies to wind stress over time. This study hypothesizes that the primary reason why the wind stress does negative work on eddies is that the direction of the wind stress is inconsistent with the direction of an eddy's velocity. However, once the eddy gradually evolves in response to the wind stress, the wind would be able to perform positive work on the eddy through an injection of energy. Consequently, relative wind stress, will no longer be an 'eddy killer'. To test this hypothesis, this study considers an idealized eddy under the influence of a continuous and steady wind field to calculate the power of the relative wind stress on an oceanic eddy. Through the time integration of the wind work on the eddy, the mechanism behind the adaptive adjustment of the eddy flow field due to wind energy input can be revealed.

The rest of this paper is structured as follows: "Assumptions" section describes the assumptions. "Response of an eddy to wind stress" section presents the main results.
"Discussion" section is the discussion, and "Conclusions" section provides the conclusions.

\section{Assumptions}

Suppose the radius $\left(R_{e 0}\right)$ of an ideal cyclonic eddy is $30 \mathrm{~km}$, where $r(x, y)\left(r=\sqrt{x^{2}+y^{2}} \leq R_{e 0}\right)$ represents the distance from the center of the eddy, the velocity at the center of the eddy is 0 , and the maximum value is located at the edge of the eddy, where the speed is $U_{e 0}=1 \mathrm{~m} \cdot \mathrm{s}^{-1}$, the eddy velocity $\vec{U}$ increases linearly with $r$, and the velocity component at any position $r(x, y)$ is expressed as $u(x, y)=-\frac{U_{e 0}}{R_{e 0}} \cdot y$, $v(x, y)=\frac{U_{e 0}}{R_{e 0}} \cdot x$, the unit is $m \cdot s^{-1}$, it tangentially rotates counterclockwise, and the velocity distribution can be given as shown in Fig. 1a.

Since the scale of the spatial variation of the atmospheric wind field is much larger than that of the ocean mesoscale eddy, it can be assumed that the background wind field is approximately uniformly distributed over the eddy, and that the background wind field is stationary, the intensity of wind field $\vec{U}_{a}$ is $U_{a 0}$ which blows from the north to the south, the magnitude of the wind is $10 \mathrm{~m} \cdot \mathrm{s}^{-1}$, the components of the wind velocity can be written as $u_{a}=0, v_{a}=-U_{a 0}$, and the unit is $m \cdot s^{-1}$. Wind stress is calculated by the absolute wind stress (Eq. 3) and the relative wind stress (Eq. 2).

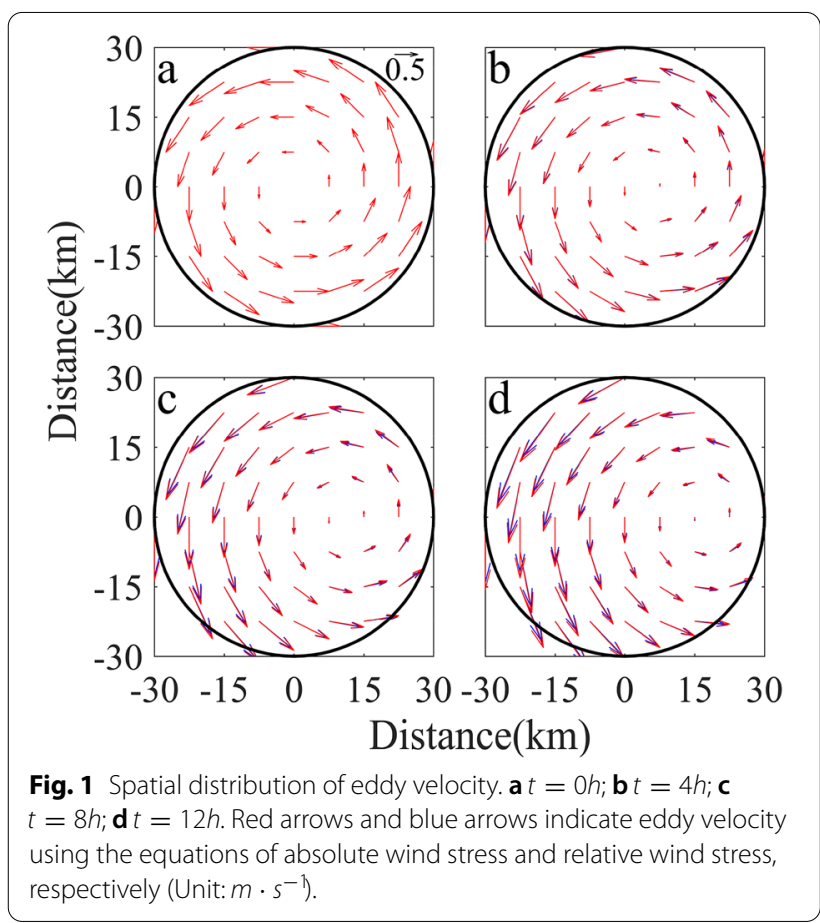




\section{Response of an eddy to wind stress}

The instantaneous work by the absolute (relative) wind stress on the above idealized eddy is plotted in Fig. 2a (2e), and it is suggested that the relative wind stress inhibits the total eddy kinetic energy growth, while the absolute wind stress does not change the energy. Here, although the eddy flow field and shape may change, these are not considered under the long-term act by wind stress. These changes may, however, also affect the magnitude and direction of wind stress, as well as the total power received from wind stress on the eddy. In this section, a steady, uniform wind is applied to the idealized eddy over a long period of time, and changes in the flow field are studied.

Considering that the water body is only affected by wind stress, it is assumed that the friction stress at the bottom of Ekman layer can be ignored, and the thickness of the Ekman layer (the deepest depth the wind stress can affect) is $D_{e}$. The vertical average velocity of water body is $\bar{U}=(\bar{u}, \bar{v})=\gamma(u, v)=\gamma \vec{U}$, where $(u, v)$ is the surface velocity. To simplify the problem of obtaining the mathematical relationship between the surface velocity and the vertical-averaged velocity in the upper layer, the vertical profile of the velocity is assumed to be linear other than exponential form as Ekman drift in the present study. By only considering the energy input by the wind stress (assuming that the Coriolis effect and pressure gradient balance do not enter the dynamic balance at the first adjustment stage), the velocity change due to the wind stress can be expressed as

$$
\frac{d \vec{U}}{d t}=\frac{\vec{\tau}}{\gamma \rho_{w} D_{e}}
$$

Integrating over time, we have

$$
\vec{U}(x, y, t)=\int_{t_{0}}^{t} \frac{\vec{\tau}(x, y, t)}{\gamma \rho_{w} D_{e}} d t+\vec{U}\left(x, y, t_{0}\right) .
$$

The spatial distribution of eddy velocity at different time steps can be obtained according to Eq. (5), as shown in Fig. 1. As can be seen from this figure, the speed on the left of the eddy increases and the speed on the right decreases. The eddy core center also gradually deviates to the right forced by both the relative and absolute wind stresses, and the velocity magnitudes forced by the absolute wind stress are slightly larger than those by the relative wind stress.

Under this condition $U_{a 0}=10 \mathrm{~m} \cdot \mathrm{s}^{-1}, U_{e 0}=1 \mathrm{~m} \cdot \mathrm{s}^{-1}$, using Eqs. (1), (2), and (5), the powers of the wind stress work at different times can be obtained. As shown in Fig. 2a, forced by the absolute wind stress, the area of negative work is equal to that of positive work at the beginning, while the area of negative work is larger than that of positive work by the relative wind stress. This result is consistent with the reports in the literature (e.g., Anderson et al., 2011; Renault et al., 2018; Flexas et al., 2019; Rai et al., 2021), in which changes in the eddy flow field and shape are not considered under the long-term act by wind stress. However, these changes may also affect the magnitude and direction of relative wind stress, as well as the total power received from the wind stress on the eddy.
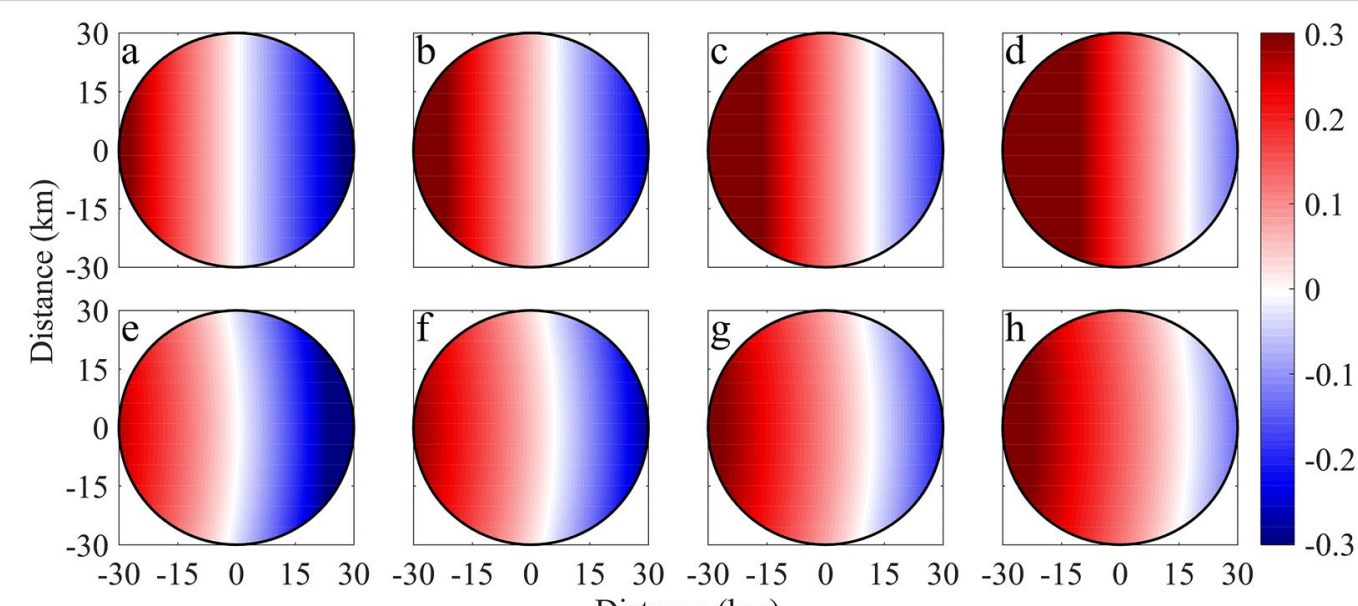

Distance $(\mathrm{km})$

Fig. 2 Spatial distribution of power forced by absolute wind stress and relative wind stress on an idealized eddy. $\mathbf{a}-\mathbf{d}$ For absolute wind stress, $\mathbf{e}-\mathbf{h}$ for relative wind stress, $(\mathbf{a})$ and $(\mathbf{e}) \mathrm{t}=0 \mathrm{~h} ;(\mathbf{b})$ and $(\mathbf{f}) \mathrm{t}=4 \mathrm{~h} ;(\mathbf{c})$ and $(\mathbf{g}) \mathrm{t}=8 \mathrm{~h} ;(\mathbf{d})$ and $(\mathbf{h}) \mathrm{t}=12 \mathrm{~h}$. Color indicates the power intensity $\left(U n i t: W \cdot m^{-2}\right)$ 
In this section, a steady, uniform wind is applied to the idealized eddy over a certain time, and changes in the flow field are studied. After $4 \mathrm{~h}$, the area of positive power gradually increases forced by both the relative and absolute wind stresses, so that the wind stress on the whole eddy area does positive work on the eddy. Figures $2 \mathrm{~b}-\mathrm{d}$ gives results for the absolute wind stress, and Fig. $2 \mathrm{f}-\mathrm{h}$ gives results for the relative wind stress. Shown in Fig. 2, due to considering the eddy velocity in the case with the relative wind stress, the zero line of the power is a curved line for the case of the relative wind stress, while it is a straight line for the case of the absolute wind stress. The temporal changes of the powers integrated in the initial eddy area forced by the relative and absolute wind stresses are plotted in Fig. 3a. Both the powers increase with time but the power forced by the absolute wind stress is zero or positive, while the power is negative before the time $1.58 \mathrm{~h}$ and then becomes positive for the case of the relative wind stress. The main reason for the increase of the positive wind work area is that the eddy velocity has changed in response to the wind stress and gradually follows the wind stress direction. The eddy velocity field adapts to the overlying wind field. Then, and only then, will wind stress do the positive work on the eddy.

As resulted from the power change with the time, Fig. 3b shows the changes of the total kinetic energy over the eddy area with the time. The KE increases with time forced by the absolute wind stress due to the power is always positive, while the KE decreases with time within the first $1.58 \mathrm{~h}$ and then increase with time forced by the relative wind stress corresponding to the power change with time in Fig. 3a. Figure $3 \mathrm{a}$ and $\mathrm{b}$ also demonstrate that the wind energy input by the relative wind stress is significantly smaller than that of the absolute wind stress.

\section{Discussion}

To examine the sensitivity of the inflection point to the wind intensity from the negative wind work to the positive wind work, the eddy KE under different wind speeds are calculated. Under different wind speed conditions $(8$,
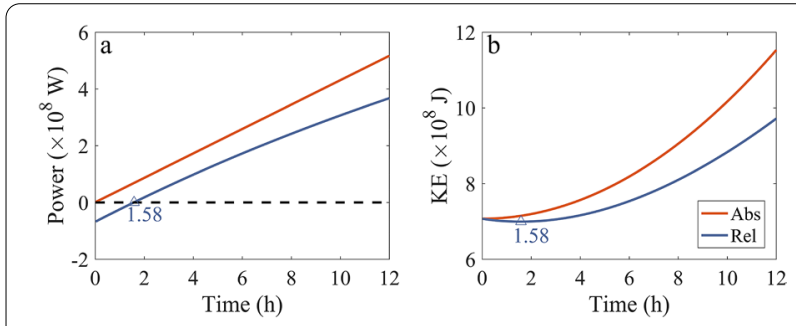

Fig. 3 Time series of power (a) and kinetic energy (b) area integration. The blue line and red line indicate relative and absolute, respectively
10 , and $\left.12 \mathrm{~m} \cdot \mathrm{s}^{-1}\right)$, the change of the total kinetic energy of the eddy with time within the initial eddy range is calculated, as shown in Fig. 4. Within 12 h, the total kinetic energy of the eddy decreases at first and then increases. The inflection points of the eddy kinetic energy is at 3.07, 1.58 , and $0.92 \mathrm{~h}$ with wind speeds of $8,10,12 \mathrm{~m} \cdot \mathrm{s}^{-1}$, respectively. It can be concluded that under the above assumption, the work of relative wind stress on the eddy is negative work first and then positive work.

From the above discussion, it can be speculated that when an eddy is generated by the wind forcing (i.e., wind curl), the eddy current flow will be aligned with the wind direction, and then the wind stress will do the positive work. The hypothesis is supported by $\mathrm{Xu}$ et al. (2016), where the authors quantifies the work of global relative wind stress on mesoscale eddies using satellite observations. They identified that work is negative in most areas but is surprisingly positive in the northeastern tropical Pacific, see Fig. 1 in Xu et al. (2016). The area is constantly forced by the wind jets over the Gulfs of Tehuantepec and Papagayo and the low-frequency wind force is suggested as the primary force for the generation of the eddies in the northeastern tropical Pacific (Liang et al. 2012). According to the theoretical analysis outlined in this paper, under the action of a long-term wind field, eddy structures have adjusted and adapted to the wind field, so that wind energy can input kinetic energy into the eddy, i.e., the wind stress does the positive work on the eddies.

\section{Conclusions}

Previous studies so far have suggested that the relative wind stress acts as a "killer" to oceanic eddies by suppressing the development of oceanic eddies. The

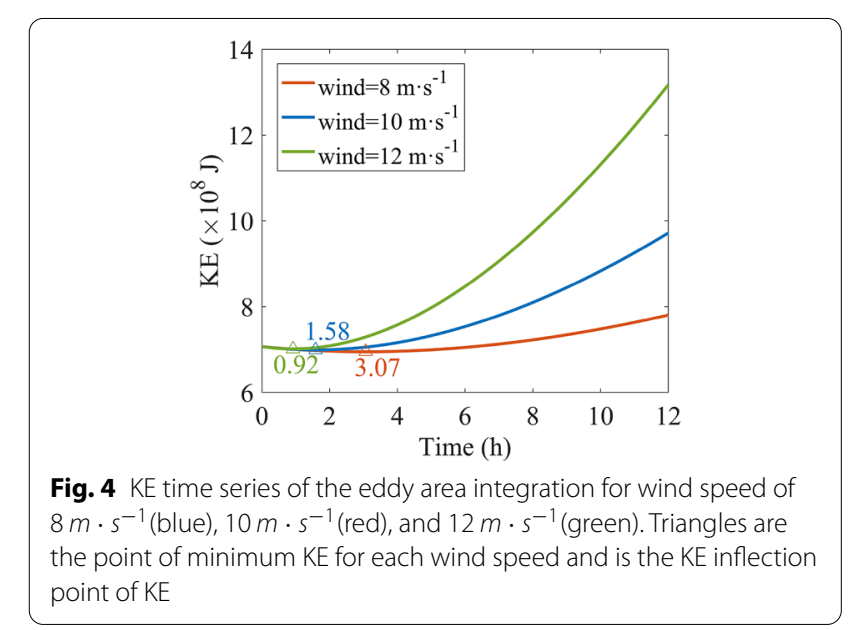


present study finds that the relative wind stress does not always damp oceanic eddies.

In this study, to explore the mechanism of the variation in wind stress work on an oceanic eddy, under an assumption that the wind stress plays a major role and other factors are ignored, we design a simplified ideal model by only considering the momentum transfer effect of atmospheric wind field on an ideal oceanic eddy. The effects of ocean mesoscale eddies on wind stress energy input are studied using two different equations of absolute and relative wind stress. It is found that at the beginning, the total power of wind stress integrated over the eddy area is 0 when the eddy velocity is not included and the total power of wind stress is negative when the eddy velocity is included. However, considering the response and adjustment of the eddy under the action of wind stress, the present research shows that the work of absolute wind stress is always positive and the work of relative wind stress is negative in the first few hours, after the inflection point, the work is positive. It implicates that when the eddy velocity field is adaptive to the wind field, the wind stress does the positive work on the eddy otherwise it will do negative work. In other words, if the eddy is generated by wind stress, such as the eddies in the southwest of Mexico in the Pacific Ocean, where the wind stress does positive work on eddies. Therefore, it can be concluded that the wind stress does not always do the negative work on an eddy. When an eddy structure is independent on the wind field, the wind stress does negative work integrated over the eddy area but when the eddy velocity field adjusts to the wind field, the wind stress does the positive work. This finding implicates that the energy input from the wind is sensitive to the mesoscale eddy velocity structure.

It should be noted that the KE of eddy cannot grow infinitely. In reality, the eddy development involves many physical processes: wind energy input, eddy and mean flow interaction, turbulent dissipation, et al. After the early stage of the adjustment, all the processes mentioned above will take effect and the eddy will finally reach an equilibrium state. The dynamic balance determines the time scale to the equilibrium. The investigation on the eddy equilibrium is beyond the scope of the present manuscript and will be left for the future study.

The present study, together with the previous relevent research, suggest that the signs (positive or negative) of relative wind stress work on oceanic eddies depend on the duration and variation frequency of the sea surface wind. The further exploration of the topic requires more extensive investigations including numerical modeling and in situ observations, which will be left for future studies.

\section{Acknowledgements}

CD is supported by the National Key Research and Development Program of China (2017YFA0604100, 2016YFC1402004 and 2017YFC1404200). AP is supported by Thermohaline Structure of the western Pacific Warm Pool and its Climatic Effects (DY135-E2-3-03), Physical Marine Environment and Typical Seamount Flow Field Structure in the western Pacific Seamount Regimes (DY135-E2-2-02). CX is jointly supported by the Key Special Project for Introduced Talents Team of Southern Marine Science and Engineering Guangdong Laboratory (Guangzhou) (GML2019ZD0304), the Strategic Priority Program on Space Science - Chinese Academy of Sciences (XDA15020901), the Natural Science Foundation of Guangdong (2017A030313233) and the Independent Research Project Program of State Key Laboratory of Tropical Oceanography (LTOZZ1902).

\section{Authors' contributions}

CD conceived and designed the study, FT has carried out the overall implementation, and FT, BJB and JJ wrote the paper. All authors discussed and contributed to the manuscript revision. All authors read and approved the final manuscript.

\section{Funding}

This work is supported by the National Key Research and Development Program of China (2017YFA0604100, 2016YFC1402004 and 2017YFC1404200), Thermohaline Structure of the western Pacific Warm Pool and its Climatic Effects (DY135-E2-3-03), Physical Marine Environment and Typical Seamount Flow Field Structure in the western Pacific Seamount Regimes (DY135E2-2-02), the Key Special Project for Introduced Talents Team of Southern Marine Science and Engineering Guangdong Laboratory (Guangzhou) (GML2019ZD0304), the Strategic Priority Program on Space Science - Chinese Academy of Sciences (XDA15020901), the Natural Science Foundation of Guangdong (2017A030313233) and the Independent Research Project Program of State Key Laboratory of Tropical Oceanography (LTOZZ1902).

Availability of data and materials

Not applicable.

\section{Declarations}

\section{Competing interests}

The authors declare that they have no competing interests.

\section{Author details}

${ }^{1}$ Oceanic Modeling and Observation Laboratory, School of Marine Sciences, Nanjing University of Information Science and Technology, Nanjing, China.

${ }^{2}$ Southern Marine Science and Engineering Guangdong Laboratory (Zhuhai), Zhuhai, China. ${ }^{3}$ Ministry of Natural Resources, Third Institute of Oceanography, Xiamen, China. ${ }^{4}$ Department of Atmospheric and Oceanic Sciences, University of California, Los Angeles, CA, USA. ${ }^{5}$ South China Sea Institute of Oceanology, Chinese Academy of Sciences, Guangzhou, China.

Received: 28 August 2021 Accepted: 19 November 2021 Published online: 05 December 2021

\footnotetext{
References

Anderson LA, McGillicuddy DJ, Maltrud ME, Lima LD, Doney SC (2011) Impact of eddy-wind interaction on eddy demographics and phytoplankton community structure in a model of the North Atlantic Ocean. Dynam Atmos Oceans 52:80-94. https://doi.org/10.1016/j.dynatmoce. 2011.01 .003

Bunker AF (1976) Computations of surface energy flux and annual air-sea interaction cycles of the North Atlantic Ocean. Mon Weath Rev 104(9):1122-1140. https://doi.org/10.1016/0146-6291(77)90038-8

Bye JA (1985) Large-scale momentum exchange in the coupled atmosphere ocean. In: Nihoul J (ed) Coupled Ocean-Atmosphere models. Elsevier Oceanography Series, vol 40. Elsevier, Amsterdam, pp 51-61

Charnock H (1955) Wind stress on a water surface. Q J R Meteorol Soc 18:639-640. https://doi.org/10.1002/qj.49708135027
} 
Dawe JT, Thompson L (2006) Effect of ocean surface currents on wind stress, heat flux, and wind power input to the ocean. Geophys Res Lett 33:L09604. https://doi.org/10.1029/2006GL025784

Dewar WK, Flierl GR (1987) Some effects of the wind on rings. J Phys Oceanogr 17:1653-1667. https://doi.org/10.1175/1520-0485(1987)017\% 3c1653:SEOTWO\%3e2.0.CO;2

Donelan MA, Haus BK, Reul N, Plant WJ, Stiassnie M, Graber HC, Brown OB, Saltzman ES (2004) On the limiting aerodynamic roughness of the ocean in very strong winds. Geophys Res Lett 31(18):355-366. https:// doi.org/10.1029/2004GL019460

Dong C, Mcwilliams JC, Liu Y, Chen D (2014) Global heat and salt transports by eddy movement. Nat Commun 5(2):3294. https://doi.org/10.1038/ ncomms4294

Duhaut TH, Straub DN (2006) Wind stress dependence on ocean surface velocity: implications for mechanical energy input to ocean circulation. J Phys Oceanogr 36(2):202-211. https://doi.org/10.1175/JPO2842.1

Faller AJ (1968) Sources of energy for the ocean circulation and a theory of the mixed layer. In: Proc. Fifth US Congress of Applied Mechanics, Minneapolis, Minnesota, ASME. pp. 651-672

Flexas MM, Thompson AF, Torres HS, Klein P, Farrar JT, Zhang H, Menemenlis D (2019) Global estimates of the energy transfer from the wind to the ocean, with emphasis on near-inertial oscillations. J Geophys Res Oceans 124(8):5723-5746. https://doi.org/10.1029/2018JC014453

Garratt JR (1977) Review of drag coefficients over oceans and continents. Mon Wea Rev 105(105):915-929. https://doi.org/10.1175/1520-0493(1977) 105\%3c0915:RODCOO\%3e2.0.CO;2

Hughes CH, Wilson C (2008) Wind work on the geostrophic ocean circulation: an observational study on the effect of small scales in the wind stress. J Geophys Res 113:C02016. https://doi.org/10.1029/2007JC004371

Kara AB, Metzger EJ, Bourassa MA (2007) Ocean current and wave effects on wind stress drag coefficient over the global ocean. Geophys Res Lett 34:L01604. https://doi.org/10.1029/2006GL02784

Liang J, McWilliams JC, Kurian J, Colas F, Wang P (2012) Mesoscale variability in the northeastern tropical Pacific: forcing mechanisms and eddy properties J. Geophys Res Oceans 117(C7):C07003. https://doi.org/10.1029/ 2012JC008008

Makin VK (2005) A note on the drag of the sea surface at hurricane winds. Bound Lay Meteorol 115(1):169-176. https://doi.org/10.1007/ s10546-004-3647-x

Oort AH, Anderson LA, Peixoto JP (1994) Estimates of the energy cycle of the oceans. J Geophys Res 99(C4):7665-7688. https://doi.org/10.1029/93JC0 3556

Pacanowski RC (1987) Effect of equatorial currents on surface stress. J Phys Oceanogr 17:833-838. https://doi.org/10.1175/1520-0485(1987)017\% 3c0833:EOECOS\%3e2.0.CO;2

Powell MD, Vickery PJ, Reinhold TA (2003) Reduced drag coefficient for high wind speeds in tropical cyclones. Nature 422(6929):279-283. https://dol. org/10.1038/nature01481

Qin Z (1980) A contribution to the calculation of wind stress on sea surface Trans Oceanology Limn 3:1-8. https://doi.org/10.13984/j.cnki.cn37-1141. 1980.03.001 (In Chinese)

Rai S, Hecht M, Maltrud M, Aluie H (2021) Scale of oceanic eddy killing by wind from global satellite observations. Sci Adv 7:eabf4920. https://doi.org/10. 1126/sciadv.abf4920

Renault L, Molemaker MJ, Mcwilliams JC, Shchepetkin AF (2016) Modulation of wind work by oceanic current interaction with the atmosphere. J Phys Oceanogr 46:1685-1704. https://doi.org/10.1175/JPO-D-15-0232.1

Renault L, Marchesiello P, Masson S, Mcwilliams JC (2018) Remarkable contro of western boundary currents by Eddy killing, a mechanical air-sea coupling process. Geophys Res Lett 46:2743-2751. https://doi.org/10.1029/ 2018GL081211

Scott RB, Xu Y (2009) An update on the wind power input to the surface geostrophic flow of the World Ocean. Deep Sea Res Part I Oceanogr Res Pap 56(9):295-304. https://doi.org/10.1016/j.dsr.2008.09.010

Wu J (1980) Wind-Stress coefficients over Sea surface near neutral conditions-a revisit. J Phys Oceanogr 10(5):727-740. https://doi.org/10.1175/ 1520-0485(1980)010\%3c0727:WSCOSS\%3e2.0.CO;2

Wunsch C (1998) The work done by the wind on the oceanic general circulation. J Phys Oceanogr 28(11):2332-2340. https://doi.org/10.1175/15200485(1998)028\%3c2332:TWDBTW\%3e2.0.CO;2
Xu C, Zhai X, Shang X (2016) Work done by atmospheric winds on mesoscale ocean eddies. Geophys Res Lett 43(12):174-180. https://doi.org/10.1002/ 2016GL071275

Yu Z, Fan Y, Metzger EJ (2018) The impact of ocean surface currents on global eddy kinetic energy via the wind stress formulation. Ocean Modell 130:29-39. https://doi.org/10.1016/j.ocemod.2018.07.009

Zhai X, Greatbatch RJ (2007) Wind work in a model of the northwest Atlantic Ocean. Geophys Res Lett 34:L04606. https://doi.org/10.1029/2006GL0289 07

Zhai X, Johnson HL, Marshall DP, Wunsch C (2012) On the wind power input to the ocean general circulation. J Phys Oceanogr 42:1357-1365. https://doi. org/10.1175/JPO-D-12-09.1

Zhao ZK, Liu C, Li Q, Dai G, Song Q, Lv W (2015) Typhoon air-sea drag coefficient in coastal regions. J Geophys Res: Oceans 120(2):716-727. https:// doi.org/10.1002/2014JC010283

\section{Publisher's Note}

Springer Nature remains neutral with regard to jurisdictional claims in published maps and institutional affiliations.

\section{Submit your manuscript to a SpringerOpen ${ }^{\odot}$ journal and benefit from:}

- Convenient online submission

- Rigorous peer review

- Open access: articles freely available online

- High visibility within the field

- Retaining the copyright to your article

Submit your next manuscript at $\boldsymbol{\nabla}$ springeropen.com 